\title{
Commentary Weakness in the ICU: a call to action
}

\author{
Robert D Stevens ${ }^{1}$, Nicholas Hart ${ }^{2}$, Bernard de Jonghe ${ }^{3}$ and Tarek Sharshar ${ }^{4}$
}

\author{
${ }^{1}$ Departments of Anesthesiology and Critical Care Medicine; Neurology; Neurosurgery; and Radiology, Johns Hopkins University School of Medicine, \\ Baltimore, Maryland 21287, USA \\ 2Lane Fox Respiratory Unit, National Institute of Health Research Comprehensive Biomedical Research Centre, Guy's \& St Thomas' NHS Foundation \\ Trust and King's College, London SE1 7EH, UK \\ ${ }^{3}$ Réanimation Médico-Chirurgicale, Centre Hospitalier de Poissy-Saint-Germain, Poissy 78300, France \\ ${ }^{4}$ Department of Intensive Care Medicine, AP-HP, Hôpital Raymond Poincaré, Université Versailles Saint-Quentin en Yvelines, Garches 92380 , France
}

Corresponding author: Robert D Stevens, rstevens@jhmi.edu

Published: 9 November 2009

Critical Care 2009, 13:1002 (doi:10.1186/cc8143)

This article is online at http://ccforum.com/content/13/6/1002

(c) 2009 BioMed Central Ltd

See related research by Gerovasili et al., http://ccforum.com/content/13/5/R161

\begin{abstract}
Muscle weakness is prevalent in critically ill patients and can have a dramatic effect on short- and long-term outcomes, yet there are currently no interventions with proven efficacy in preventing or treating this complication. In a new randomized trial, researchers found that serial electrical muscle stimulation significantly mitigated ultrasound-defined muscle atrophy, and the treatment was not linked to adverse effects. Although preliminary, these results, together with other recent studies, indicate a paradigm shift to a proactive approach in managing neuromuscular complications in the ICU.
\end{abstract}

In a recent issue of Critical Care, Gerovasili and colleagues [1] present results of a randomized controlled trial of electrical muscle stimulation (EMS) to reduce muscle wasting in critically ill patients. Muscle weakness is a frequent and serious manifestation of critical illness, independently linked to a higher risk of death during hospitalization [2]. Patients with ICU-acquired weakness (ICUAW) remain longer on mechanical ventilation, and their hospital stay is protracted and costly [3]. Persisting muscle weakness is a leading complaint in survivors of critical illness [4], and electrophysiological studies document evidence of polyneuropathy and/or myopathy that can endure months to years after the acute illness [5]. Although the burden of these outcomes is increasingly appreciated, little progress has been made in identifying and validating treatment options for ICUAW, a situation that has contributed to a sense of therapeutic nihilism among clinicians. New clinical trials are challenging this perception.

The management of ICUAW has traditionally emphasized efforts to minimize or avoid exposure to postulated systemic risk factors such as neuromuscular blockers and gluco- corticoids (although it has never been demonstrated that a strategy of deliberately withholding these agents is beneficial). There is also substantial evidence of a link between ICUAW and stress hyperglycemia. In a systematic review, hyperglycemia or poor glycemic control was associated with ICUAW in five of six studies [6]. Two large randomized trials of intensive insulin therapy in the ICU found that electrophysiological abnormalities suggestive of polyneuropathy were less common in patients receiving tight glycemic control [7]. Another key development has been a growing appreciation of the benefits of early mobility in critically ill patients. Bed rest and immobilization, when prolonged beyond a few hours, are known to alter fundamental aspects of muscle biology, structure, and function. In preclinical models, mechanical unloading of muscles results in oxidative stress, imbalances in protein synthesis/degradation, and cell death [8], pathological responses that may be compounded by systemic inflammation, infection, hypercortisolemia, and malnutrition [9]. In healthy volunteers and in critically ill patients, bed rest is associated with a rapid loss of muscle mass and strength. The implementation of methods to counter the effects of bed rest and immobility represents an important new therapeutic paradigm. Novel approaches that have been evaluated in critically ill patients include scheduled sedation or coupled sedation interruption and spontaneous breathing trials [10], EMS [1], bedside exercises such as cycling [11], and early mobilization and ambulation [12].

EMS, in which electrical current is applied transdermally to induce muscle contraction, has been used to maintain or increase muscle performance and measures of functional status in patients with chronic obstructive pulmonary disease or congestive heart failure who have limited exercise capacity 
[13]. Earlier studies in critically ill patients suggested that treatment with EMS reduced excretion of amino acids associated with muscle catabolism [14]. Gerovasili and colleagues applied EMS daily to bilateral quadriceps and peroneus longus muscles during a 7-day period, and muscle mass was estimated ultrasonographically by quadriceps crosssectional diameter. Quadriceps cross-sectional diameter decreased significantly less in patients treated with EMS than in controls, suggesting that EMS mitigated the loss of muscle mass associated with immobility and critical illness.

We must appreciate that this is pilot work with methodological limitations. The study was not blinded, lacked a sham control group, included patients with neurologic disease (with more in the control group), and importantly did not include any clinical or electrophysiological assessment of muscle function to correlate with the ultrasound assessments. Seymour and colleagues [15] have found a good correlation between quadriceps cross-sectional area and strength, but this needs to be validated in critically ill patients. It is also notable that 12 patients were excluded because of tissue edema impeding ultrasound analysis; the exclusion of these patients is problematic, since tissue edema may be a marker for conditions (for example, sepsis, inadequate nutrition) that can confound the preservation of muscle mass. Finally (and curiously), the treatment effect of EMS was noted to be significant only on one side. Notwithstanding, the technique is reported to be safe, and the results are sufficiently interesting to warrant more clinical trials evaluating the effects of EMS in ICU patients, particularly in those who are unable to participate in early mobilization because of concurrent encephalopathy, sedation, or musculoskeletal injury. These studies will need to assess a range of questions, including: what is the clinical effect of EMS - namely, is the preservation in muscle mass corroborated by beneficial effects on muscle strength, needle electromyography, and on functional status? Which patients are most likely to tolerate and benefit from EMS? Will stimulation of muscle be helpful in patients with, or at risk for, isolated or predominant critical illness polyneuropathy? Which muscles should be stimulated? What should be the interval between EMS sessions and the duration of EMS therapy? What should be the magnitude of stimulation (in previous studies of EMS, treatment effects did not correlate closely with the intensity of stimulation)?

In summary, there is little doubt that ICUAW is a grave complication, but new data indicate that its severity can be reduced through the timely implementation of selected rehabilitative measures. If the benefits of EMS - or of other forms of muscle stimulation, such as magnetic stimulation - is confirmed, this technique will become an important complement to current strategies for early physical therapy and mobilization in the ICU.

\section{Competing interests}

The authors declare that they have no competing interests.

\section{References}

1. Gerovasili V, Stefanidis K, Vitzilaios K, Karatzanos E, Politis E, Koroneos A, Chatzimichail A, Routsi C, Roussos C, Nanas S: Electrical muscle stimulation preserves the muscle mass of critically ill patients. A randomized study. Crit Care 2009, 13:R161.

2. Sharshar T, Bastuji-Garin S, Stevens RD, Durand MC, Malissin I, Rodriguez P, Cerf C, Outin H, De Jonghe B: Presence and severity of intensive care unit-acquired paresis at time of awakening are associated with increased intensive care unit and hospital mortality. Crit Care Med 2009, in press.

3. De Jonghe B, Bastuji-Garin S, Durand MC, Malissin I, Rodrigues $\mathrm{P}$, Cerf $\mathrm{C}$, Outin $\mathrm{H}$, Sharshar T: Respiratory weakness is associated with limb weakness and delayed weaning in critical illness. Crit Care Med 2007, 35:2007-2015.

4. Herridge MS, Cheung AM, Tansey CM, Matte-Martyn A, DiazGranados N, Al-Saidi F, Cooper AB, Guest CB, Mazer CD, Mehta S, Stewart TE, Barr A, Cook D, Slutsky AS; Canadian Critical Care Trials Group: One-year outcomes in survivors of the acute respiratory distress syndrome. N Engl J Med 2003, 348:683-693.

5. Fletcher SN, Kennedy DD, Ghosh IR, Misra VP, Kiff K, Coakley JH, Hinds CJ: Persistent neuromuscular and neurophysiologic abnormalities in long-term survivors of prolonged critical illness. Crit Care Med 2003, 31:1012-1016.

6. Stevens RD, Dowdy DW, Michaels RK, Mendez-Tellez PA, Pronovost PJ, Needham DM: Neuromuscular dysfunction acquired in critical illness: a systematic review. Intensive Care Med 2007, 33:1876-1891.

7. Hermans G, De Jonghe B, Bruyninckx F, Van den Berghe G: Interventions for preventing critical illness polyneuropathy and critical illness myopathy. Cochrane Database Syst Rev 2009:CD006832.

8. Phillips SM, Glover El, Rennie MJ: Alterations of protein turnover underlying disuse atrophy in human skeletal muscle. J Appl Physiol 2009, 107:645-654.

9. Fink $H$, Helming M, Unterbuchner C, Lenz A, Neff F, Martyn JA, Blobner $M$ : Systemic inflammatory response syndrome increases immobility-induced neuromuscular weakness. Crit Care Med 2008, 36:910-916.

10. Girard TD, Kress JP, Fuchs BD, Thomason JW, Schweickert WD Pun BT, Taichman DB, Dunn JG, Pohlman AS, Kinniry PA, Jackson JC, Canonico AE, Light RW, Shintani AK, Thompson JL, Gordon SM, Hall JB, Dittus RS, Bernard GR, Ely EW: Efficacy and safety of a paired sedation and ventilator weaning protocol for mechanically ventilated patients in intensive care (Awakening and Breathing Controlled trial): a randomised controlled trial. Lancet 2008, 371:126-134.

11. Burtin C, Clerckx B, Robbeets C, Ferdinande P, Langer D, Troosters T, Hermans G, Decramer M, Gosselink R: Early exercise in critically ill patients enhances short-term functional recovery. Crit Care Med 2009, 37:2499-2505.

12. Morris PE, Goad A, Thompson C, Taylor K, Harry B, Passmore L, Ross A, Anderson L, Baker S, Sanchez M, Penley L, Howard A, Dixon L, Leach S, Small R, Hite RD, Haponik E: Early intensive care unit mobility therapy in the treatment of acute respiratory failure. Crit Care Med 2008, 36:2238-2243.

13. Sillen MJ, Speksnijder CM, Eterman RM, Janssen PP, Wagers SS Wouters EF, Uszko-Lencer NH, Spruit MA: Effects of neuromuscular electrical stimulation of muscles of ambulation in patients with chronic heart failure or COPD: a systematic review of the English-language literature. Chest 2009, 136:44-61.

14. Bouletreau P, Patricot MC, Saudin F, Guiraud M, Mathian B: Effects of intermittent electrical stimulations on muscle catabolism in intensive care patients. JPEN J Parenter Enteral Nutr 1987, 11:552-555.

15. Seymour JM, Ward K, Sidhu PS, Puthucheary Z, Steier J, Jolley CJ, Rafferty G, Polkey MI, Moxham J: Ultrasound measurement of rectus femoris cross-sectional area and the relationship with quadriceps strength in COPD. Thorax 2009, 64:418-423. 